\title{
Retraction Note to: Gallstone ileus an unusual reason for right iliac fossa pain in Crohn's disease: a case report
}

Sheharyar Asif Qureshi ${ }^{1 *}$, Rashaad Gossiel ${ }^{2}$ and Mehwish Qureshi ${ }^{3}$

\section{Retraction note}

This article [1] has been retracted by the publisher because it was republished in the journal [2] due to an error during transfer of the journal between publishers in 2009. BioMed Central apologizes to the authors and readers for this error and for any inconvenience caused.

\footnotetext{
Author details

'Department of Acute Medicine, Queens Medical Centre, Nottingham University Hospitals, Derby Road, Nottingham, UK. ${ }^{2}$ Emergency Admissions Unit, Lincoln County Hospital, United Lincolnshire NHS Trust, Greetwell road, Lincoln, UK. ${ }^{3}$ Department of Psychiatry, Birmingham Children Hospital, Birmingham and Heartlands NHS Trust, Birmingham, UK.
}

\section{References}

1. Qureshi SA, Gossiel R, Qureshi M. Gallstone ileus an unusual reason for right iliac fossa pain in Crohn's disease: a case report. Cases J. 2009;2:9142.

2. Qureshi SA, Gossiel R, Qureshi M. Gallstone ileus an unusual reason for right iliac fossa pain in Crohn's disease: a case report. Cases J. 2009;2:9285.

\footnotetext{
* Correspondence: drsheharyarasif@gmail.com

'Department of Acute Medicine, Queens Medical Centre, Nottingham

University Hospitals, Derby Road, Nottingham, UK

Full list of author information is available at the end of the article
} 